\title{
COMPETITIVE ADVANTAGE ANALYSIS: A NOVEL METHOD FOR INDUSTRIAL CLUSTERS IDENTIFICATION
}

\author{
Jan Stejskal ${ }^{1}$, Petr Hajek ${ }^{2}$ \\ Faculty of Economics and Administration, University of Pardubice, \\ Studentská 84, Pardubice, Czech Republic \\ E-mails: 1jan.stejskal@upce.cz; ${ }^{2}$ petr.hajek@upce.cz (corresponding author)
}

Received 09 March 2011; accepted 29 May 2011

\begin{abstract}
Many regions and their representatives decide on the amount of support they will provide to industrial clusters, their births, and their existing phase based on the public budget. Nowadays the efficiency of public spending must be provided. There are many examples showing situations where industrial clusters were cancelled when public support was limited or no longer available. Through the use of a special diagnostic method, one can find out if the industrial cluster is able to rise and also be viable without massive public budget support. The suggestion of a new method for industrial cluster identification is the aim of this paper. The Porter's diamond model of the cluster's competitiveness environment is the substance of the novel method.
\end{abstract}

Keywords: industrial clusters, competitive advantage analysis, Porter diamond model, hierarchical principal component analysis.

Reference to this paper should be made as follows: Stejskal, J.; Hajek, P. 2012. Competitive advantage analysis: a novel method for industrial clusters identification, Journal of Business Economics and Management 13(2): 344-365.

JEL Classification: C38, O18, O33.

\section{Introduction}

The changes in global economy, which is very often named "knowledge based economy", are not a direct cause for the geographical concentration of firms. The economic world of today is stiring priorities toward innovation, an outcome of network cooperation and the commutation of social capital within this network. In the global world, based on highly developed communication and transport technologies, the meaning of spatial proximity is socially determined (Bojar 2007).

Regional policy has been recognized as a policy which contributes to competitiveness. Regions are recognized as actors which make political and economic decisions, and whose local knowledge can be harnessed to improve the performance of world economy. Research and innovation represent the drivers of productivity and growth. As a result, they are the engines of regional development (Skokan 2008; Ginevicius 2010). 
In recent years, it is possible to identify a significant shift in the "paradigm" of regional development (see Bachtler, Yuill 2001; Karlsson 2008). The traditional approach to regional development was undertaken by central governments using different subsidies for firms, infrastructure, and the location of public sector activities. In part, this has been superseded by a "contemporary" approach, characterised by decentralised intervention based on integrated regional development plans and strategies, designed and delivered by the partnerships of regional and local actors (see Table 1). There are four characteristics of these contemporary approaches in regional development. First, they have a broad sphere of action, covering a range of policy sectors: infrastructure, business development, human resources, tourism, environmental, etc. Second, the national policy versions tend to encompass economic development in all regions, not just those designated for regional policy purposes which exhibit the biggest regional disparities. Third, they tend to take a pro-active approach to development, with a multi-annual programme of measures targeted at the business environment and soft infrastructure. Lastly, they have a distinctive approach to policy implementation which is collectively negotiated, led by regional authorities and involving a wide range of partners from the local government, the voluntary sector, business, and social communities.

In this context, new theories of regional development came to the fore, especially those concerned with industrial milieux (Storper 1995; Camagni 1995) and the role of clusters, systems of innovation, and networks (Porter 1998b; Cooke 2002; Maier 2007; Stejskal 2007; Karlsson 2008; Hajkova, Hajek 2009; Nowicka-Skowron, Pachura 2010; Pachura 2010, and others). It was recognized that competitive advantage increasingly improved the ability and capacity of regions to facilitate the generation, acquisition, control, and application of knowledge and information, in the interests of innovation and marketing. Many economists and policy makers highlight regions as key sites of innovation and competitiveness in the globalising economy. Thus, regional innovation

Table 1. The shift between the contemporary and future state in regional policy

\begin{tabular}{lll}
\hline \multicolumn{1}{c}{ Contemporary state } & \multicolumn{1}{c}{ Barriers } & \multicolumn{1}{c}{ Future (dream up) state } \\
\hline $\begin{array}{l}\text { Development is based } \\
\text { on low costs }\end{array}$ & $\begin{array}{l}\text { High taxes and others } \\
\text { deliveries }\end{array}$ & $\begin{array}{l}\text { Fast reactions to economical changes } \\
\text { (also on a global view) }\end{array}$ \\
\hline $\begin{array}{l}\text { Production technologies } \\
\text { are on a low level }\end{array}$ & $\begin{array}{l}\text { Bureaucracy and fast } \\
\text { changes in regulations }\end{array}$ & $\begin{array}{l}\text { Development of regions based on } \\
\text { knowledge and high technologies }\end{array}$ \\
\hline $\begin{array}{l}\text { Innovation ability } \\
\text { is very low }\end{array}$ & $\begin{array}{l}\text { Low enforceability } \\
\text { of the regulations }\end{array}$ & $\begin{array}{l}\text { High level of progression } \\
\text { in innovations and flexibility } \\
\text { in production }\end{array}$ \\
\hline $\begin{array}{l}\text { Effective connectivity } \\
\text { among firms does } \\
\text { not exist }\end{array}$ & Corruption & $\begin{array}{l}\text { Internal connected innovation systems } \\
\text { which enable many impulses for the } \\
\text { creation of innovations }\end{array}$ \\
\hline $\begin{array}{l}\text { Low effectiveness } \\
\text { of public research }\end{array}$ & $\begin{array}{l}\text { Low motivation for } \\
\text { innovations and cluster } \\
\text { birth }\end{array}$ & $\begin{array}{l}\text { High level of positive reactions from } \\
\text { the regional actors for collective needs }\end{array}$ \\
\hline
\end{tabular}

Source: according to Rehak and Pastor 2008 
systems (Cooke et al. 1997; Braczyk et al. 1998; Hajkova, Hajek 2011) are seen as an increasingly important policy framework for long-term realization of innovation based regional development strategies, including clusters (Skokan 2008).

In our previous research, we developed the method of competitive advantage analysis (Stejskal, Hajek 2008; Stejskal 2009). In this paper, we extend this method by using hierarchical multi-block principal component analysis in order to capture and model the relations between the selected factors of industrial clusters development.

This paper is structured as follows. First, clusters will be introduced as a phenomenon of the contemporary regional policy conception. Second, industrial clusters identification methods will be characterised. These methods are used with the intention not to waste the public finances provided for cluster birth and existing subsidies. Several of these methods were originally not used for cluster identification (they were used for localization, specialization, and agglomeration measurements). All the methods can be divided into two basic groups, quantitative and qualitative. Therefore the objective of this paper is to find a new method (method of competitive advantage analysis) which combines the benefits of both approaches in a more suitable way.

\section{Clusters as phenomenon of contemporary regional policy conception}

Start-up firms and young firms are regarded to be a driving force of innovation and regional development (Reynolds et al. 1994; Fritsch, Mueller 2004; Sternberg 2007; Karlsson 2008). They are acknowledged to play the crucial role of key innovation agents, in particular in knowledge based industries, reflecting the dominance of an entrepreneurial regime (Cooke 2002). It has been argued that young firms, notably academic spin-offs, innovate more radically, drawing on and exploiting commercially the knowledge and expertise generated in universities and research organizations. It is often assumed that they are rather strongly embedded in the local innovative milieu in this context, benefiting from local knowledge providers and innovation interactions, pointing to a crucial importance of local clusters. Older and more established firms, in contrast, are said to innovate less and in a more incremental way, and they seem to rely more on networks for knowledge exploitation; i.e. linkages along the value chain, which can often be found at higher spatial levels (Tödtling et al. 2007).

The phenomenon of territorial concentration of firms can not be perceived as an entirely new issue. Already at the end of the $19^{\text {th }}$ century companies using advanced technology were concentrating inside areas with a high potential of qualified labour force. Such areas were created both by companies and technological universities (Marshall 1890). This trend is, to some extent, convergent with today's theory and practice of regional innovative clusters. Besides the highly qualified labour force, the development of so called "engine industries" (for example in the following industries: automobile, aircraft, space, etc.), which attracts a large amount of small suppliers, can be considered as a reason for the development of regional clusters. Although there are different definitions of clusters, it is generally agreed that clusters are a collection of companies that are geographically co-located and interrelated (Porter 1998). 
According to Porter (1990, 1998), local competition creates incentives to emulate best practices and boost pressures to innovate, while also connecting the strengths of competition with the virtues of selective cooperation. The concept of clusters was related to the "competitiveness" of industries and of nations.

Clusters are a geographically proximate group of interconnected companies and associated institutions in a particular field linked by commonalities and complementarities. Clusters encompass an array of linked industries and other entities important to competition (...) including governmental and other institutions, such as: universities, standard setting agencies, think tanks, vocational training providers, and trade associations (Porter 1998).

A major break-through for the cluster concept was Porter's Competitive Advantage of Nations (1990) which, conversely to the prevailing US local development objective of promoting diversified economies, advocated specialisation according to historical strength by emphasising the power of industrial clusters. Porter highlighted that multiple factors beyond the ones internal to the firm may improve its performance. In his "diamond model" (illustrated in Fig. 1), four sets of interrelated forces are brought forward to explain industrial dynamics. These are associated with factor input conditions, sophisticated local demand conditions, related and supported industries, and firm structure, strategy and rivalry (Andersson et al. 2004).

The Porter diamond model describes the micro-economic background of each industrial cluster especially and, moreover, individual determinants of the effectiveness of clusters and their existence. The Porters' forces show a list of fundamental elements which are presented in each case. According to Porter, the competitiveness among firms in an industry may lead to an increase in the productivity and development of both the firms and the industry as a whole. It has been proved, that the firm or industry competitiveness in the region can be achieved based on the effects of the four forces. The possible absence

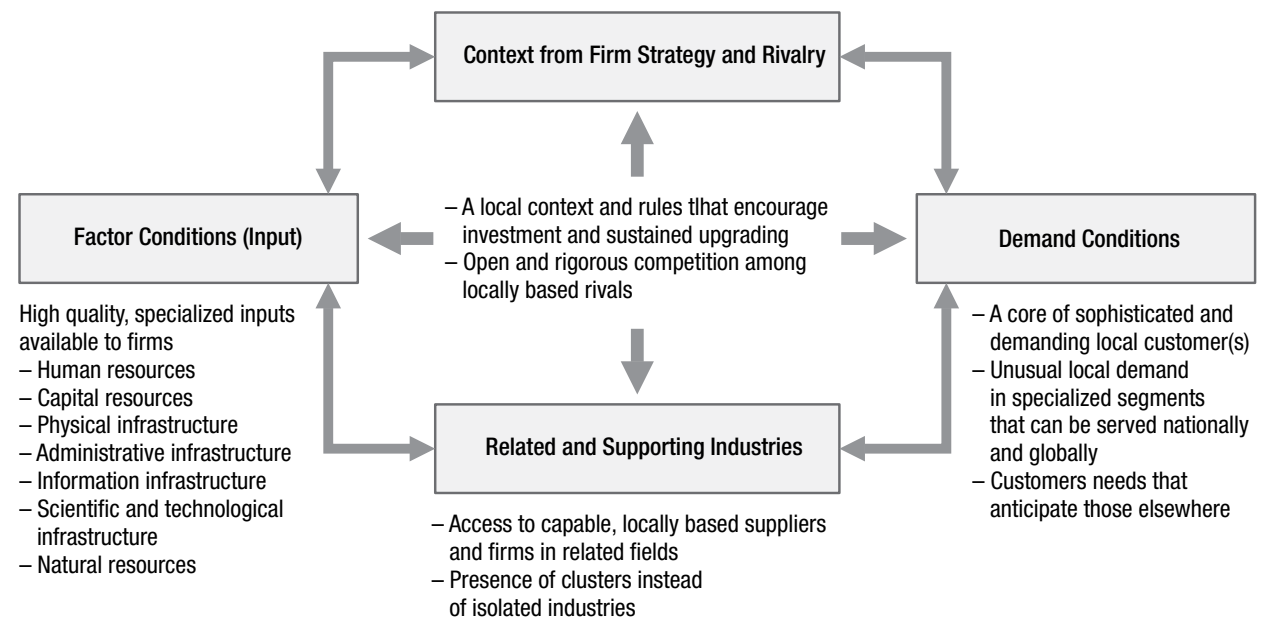

Fig. 1. Porter diamond model Source: Porter (1990) 
of certain elements (forces) affecting the current competitiveness within a region have to be taken into account (as well as the influence of other determinants such as foreign direct investment or government). The competitive advantage of the industrial cluster does not depend on the individual elements of the "diamond" (of the individual firms and other subjects), but on the consistency of the whole "diamond".

Clusters are established by a facilitator from a public administration office, university or connected firms. But the reality of establishing shows that clusters need some extra money for their birth processes. Grants flow from the budgets of regional or national governments. This is the reason for the exploration of methods in cluster identification. The effectiveness of public spending urges us to use only the most effective methods. But are the regional governments and actors of clustering process able to find out whether the birthing cluster has the possibility of continuing its existence and meeting its objectives (innovation production)?

We exactly know that Porter's diamond thesis has four determinants, but only one of them is really a clustering determinant "related and supporting industries", the rest are micro-economic characteristics (they exist without the fact that the cluster does or does not exist in economy). We state that if the cluster would birth, the conditions and presumptions for its existence must be created. But these conditions and presumptions must be embedded in the local or regional economy and we must be treated in the same way as the specialized "clustering" one.

Every operating cluster has some common characteristics (Bergmann, Feser 1999):

(1) clusters are managed by entrepreneurs and public subjects,

(2) cooperation and competition are fundamental,

(3) fixed relations between companies and public administration institutions,

(4) a cluster is a system where every member is of the same importance,

(5) cluster members have the common technologies, customers, distribution channels or labour markets, and human capital.

We consider the Porter's model of competitive advantage as an appropriate fundament for the analysis of industrial cluster potential in the regions. All the forces of the "diamond" guarantee that the analyzed cluster corresponds to the Porter definition (the so-called Porterian cluster), i.e. it will be established based on competitiveness and innovation production. It also allows analyzing the forces individually and competently assessing the region's potential for the emergence Porterian cluster.

An industrial cluster is a geographic concentration of similar, related, or complementary companies which have active channels for business transactions, communications, and dialogs. They share specialized infrastructure, labour markets, and services. They oppose the same treats and opportunities (OECD 2001). Clusters can contribute to the economic growth of both the cluster members and the whole region. This is possible due to following reasons:

(1) clusters increase productivity through the possibility of having access to specialized inputs (including human capital), information, and institutions, 
(2) clusters increase innovative capacities (due to competitiveness inside the cluster),

(3) clusters stimulate quick production and attract new firms to the cluster,

(4) clusters make regional strategic planning of higher quality possible; this is caused by knowledge of the entrepreneur environment.

The cluster and innovative potential are the integration of two fundamental parts of one of Porter's thesis "the cluster is a presumption of innovations". If we define that the existing cluster is the presumption of the innovation's birth, we would like to be able to measure the ability or capacity for cluster existing in a regional or spatial framework.

\section{Industrial clusters identification methods}

This part of the paper introduces a brief overview of the methods used for industrial clusters identification in prior studies. This overview represents an extension of the overview presented in Stejskal (2011).

Many regional scientists (Porter 1998b; Feser, Bergmann 2000; Blien, Maier 2008; and many others) patronize the idea of diversifying the methods of identification according to what level the clusters are analyzed. Cluster potential must be integrated with the development of competitive advantage which was defined by Porter in his diamond (see Porter 1998). Generally this potential conception can be identified with:

- development ability in the future,

- ability to "move" local (regional or national) economy,

- making space for new birth in innovation,

- creating some vacancies.

Cluster potential is a useful tool in the rating of industrial branches and for identifying new trends. This concept can be used also in business, industrial branches and regions. A reason for measuring cluster potential or finding out whether the cluster can be created in this region is the fact that cluster birth is very expensive; the creators must have the assurance that the money will not go to waste (see the study in Maier 2007).

Clusters can be identified at various levels of analysis. This analysis offers a new way of both thinking about the economy and organizing economic development efforts; it overcomes some of the limitations of traditional sectoral analysis. Clusters methodologies also differ in their use of techniques: (1) input-output analysis, (2) graph analysis, (3) correspondence analysis, and (4) the qualitative case study approach along the lines of the Porter studies conducted in various countries. Also the Porter's diamond method can be included in this group of methodologies.

For cluster identification two approaches can be used in general (Zizka 2004; Pavelkova 2009):

a) the first approach follows the identification of key industrial branches that may have a potential (or real) competitive advantage; this identification is followed by the statistics data analysis (mostly quantitative data),

b) the second approach investigates the internal processes and relations among existing firms; it uses the qualitative data obtained from interviews or questionnaires. 
The combination of both presented approaches is the most effective process. In this case the missing data can be compensated using the second approach, and concrete relations and their implications can be understood. In specialized industrial branches, this approach must be realized in cluster potential ${ }^{1}$ analysis.

In the identification of the industrial branch and clustered firms, Porter also sets institutions that can provide specialized and qualified labour force, technologies, information, knowledge, capital or infrastructure, and some other collective boards with the actors of cluster. These actors can influence the whole cluster, for example, with money (grants) from the public budget in the cluster birth phase.

Anderson (1994) provides a list of steps for the identification of cluster in regions:

1) Definition of region for analysis: the main relations among firms, local government, and institutions must be realized in this region; the other type of cluster is defined by actors (not only geographically); these actors can come from other regions, but they are connected with relations inside the cluster.

2) Analysis of selected indicators (unemployment, export, added value, turnover, benefit) in important industrial branches where the concentration can be found; here the coefficient of specialization or localization (agglomeration) can be used.

3) Identification and selection of probable groups in export branches where the relations are identified; the reason for this step is to set a group of clustered subjects that can introduce the suppliers of inputs, components, and services connected with the main production of the cluster.

4) Cluster definition determination is the next step; during this step interviews with managers of all actors must be realized in order to conduct the analyses where various data is needed.

5) Cluster map increasing is the next step; the graphical visualization of the industrial branch and relations within the cluster in the region can be made.

6) Function of cluster for the region is the last step; this step can be realized continuously.

There are many other tools for cluster identification in literature and other sources. According to the above mentioned two fundamental ways, the methods can be divided into two groups, qualitative and quantitative.

Among quantitative methods we include:

a) specialization and localization quotients,

b) input-output analysis (various well known approaches; Clemson University and Wiskonsin approach; for recent development see e.g. Titze et al. 2011),

c) shift-share analysis,

d) Gini coefficient of localization,

e) Ellison-Glaeser index of agglomeration (Ellison, Glaeser 1997),

f) Maurel-Sédillot index (Maurel, Sédillot 1999).

\footnotetext{
1 "cluster potential" expresses the configuration of the socio-economic elements in a region that permits the cluster birth and existence. The higher the cluster potential, the higher the probability of cluster birth in the analysed industrial branch.
} 
Qualitative methods are represented by:

a) interviews with experts and management of the firms,

b) researches by questionnaires,

c) case studies.

Bergmann and Feser 1999 also have their own list of methods:

a) expert examination,

b) specialization indexes,

c) input-output analysis for business relations,

d) input-output analysis for innovations (unsuitable for cluster identification),

e) network analysis, graph theory (rather tool for visualization),

f) statistical and economical overviews.

Among the presented methods, there are some which integrate in themselves some mechanisms from other methods. The Elison-Glaeser index is a clear example; it integrates geographic concentration, industrial concentration index and Hirschmann-Herfindahl index. That is why we can define other methods for cluster identification:

- diversity index (RDI) for the measurement of regional industrial specialization according to (Duranton, Puga 2000),

- index of geographic concentration measuring geographic concentration or spatial distribution of national industries.

Another taxonomy of the methods for cluster identification can be found in Goetz et al. 2007. They grouped the methods into AHP (analytical hierarchy procedure) methods and CBM (community-business matching) model.

Each of the methods gives specific results, and their interpretation is the most important phase of the whole identification process of clusters or industries suitable for clustering. Sternberg and Litzenberger (2004) distinguish between bottom-up and top-down approaches. Bottom-up approaches are represented by expert opinions or social network analysis. Top-down approaches include (Brachert et al. 2011):

- measures of spatial concentration such as Gini coefficient and Hirschmann-Herfindahl index of concentration (Titze et al. 2011),

- location quotients, cluster index (Sternberg, Litzenberger 2004) and Ellison-Glaeser index,

- input-output methods.

Luo and Yan (2009) used input-output analysis (the so-called maximum method) for the identification of Chinese industrial clusters. Brenner (2001) simulated the evolution of localised industrial clusters. He concluded that those industries are more likely to cluster, which are characterised by a high possible growth rate of start-ups, by radical innovations, by a strong importance of experienced employees with firms as the only source of these, by a large number of spin-offs, etc. In a similar manner, Fioretti (2006) simulated the dynamics of industrial clusters by using agent-based models. 


\section{Proposed method of competitive advantage analysis}

The proposed method of competitive advantage analysis results from the Porter diamond model which describes the competitiveness model of economical environment of clusters. The model shows competitiveness in the micro-economic environment of the clusters whether the components are micro-economic or not is open to discussion.

Our method combines the above mentioned qualitative (or bottom-up) and quantitative (up-down) approaches. We can call it the method of competitive advantage analysis (for more see Stejskal, Hajek 2008). This method represents a novel method in the field of industrial clusters identification. All contemporary methods (see the up and bellow) are based on quantitative or qualitative principle and their substance is very similar (they accent only various aspect of Hirshman-Herfindahl index or Ellison-Glaeser index on one hand, or are based only on expert opinion on the other hand). The important characteristics of our method are: simplicity of calculation, portability to various environments (especially NUTS3 regions, we will discuss this issue in the conclusion) and great explanatory power (the results are easy to understand).

It is conducted as follows. First, the qualitative data are collected through a survey. In this way the factors proposed by Porter are evaluated. Further, quantitative factors, represented by localization quotients, are calculated for each of the monitored industries. Consequently, the qualitative and quantitative factors are put together through hierarchical principal component analysis. Thus, the resulting score of competitive advantage is obtained.

This method is demanding for input data, but due to this reason it provides a good subsequent interpretability. The method can help map cluster potential in all main industrial branches in the analyzed region. The dependence on the opinions of respondents from regional firms is a disadvantage of this method. This dependence can be reduced by using a large number of questioned firms.

The method is based on interviews conducted on managers from firms in the region where we want to determine the cluster potential. In this way we obtained qualitative data based on the Porter diamond model, see Figure 1. In the questionnaire there are questions addressing the following issues:

- accessibility of specialized sources needed for production in the industrial branch (human, capital, infrastructure, nature),

- relations among the firms in the region (aggressive relations, evaluation of entrepreneur climate, etc.),

- suppliers chains (suppliers for the end customers),

- local subcontractor systems, flexibility of local firms,

- relations among the firms in the region and their branch orientation.

Every respondent evaluated the answers using a 4-point scale (positive $(+2)$, rather positive $(+1)$; rather negative $(-1)$, negative $(-2)$ ). Answers with a neutral evaluation were not included because they do not contribute to an unambiguous result (they represent a non-committal answer). The result is calculated as the sum of points for each industrial branch. The proportional result (\%) expresses the positive or negative position of the 
result on the graphic tool (tetragon). The minimum of the scale is $-100 \%$, while the maximum is $+100 \%$.

Except for the factors included in the Porter diamond model, the indicators of industrial branches' growth (input output analysis) in the competitive advantage model are also applied. Localization quotients are most frequently used for the analysis of industrial clusters. Thus, we investigate their influence on the results compared with the determinants of competiveness advantage resulting from the Porter diamond model.

Cluster potential ability can be analyzed using growth of turnover and employment (the clusters can increase the turnover of most clustered firms). The localization quotient for the number of employees is defined as follows:

$$
\mathrm{LQ}_{\mathrm{i}}=\frac{\mathrm{z}_{\mathrm{i}} / \mathrm{z}}{\mathrm{Z}_{\mathrm{i}} / \mathrm{Z}},
$$

where $L Q_{i}$ is the localization quotient of the $\mathrm{i}$-th branch (employees), $z_{i}$ is the number of employees of the $i$-th branch in a region, $z$ is the total number of employees in the region, $Z_{i}$ is the number of employees of the $i$-th branch in the country, $Z$ is the total number of employees in the country.

The LQ $>1$ describes the specialization in the i-th branch in the region. This branch employs higher ratio of labour forces than the country level.

The localization can be changed for some other outputs (for example for turnovers, value added). Then the changes are:

$$
\mathrm{LQ}_{\mathrm{i}}^{\mathrm{v}}=\frac{\mathrm{v}_{\mathrm{i}} / \mathrm{v}}{\mathrm{V}_{\mathrm{i}} / \mathrm{V}},
$$

where $\mathrm{LQ}_{\mathrm{i}}{ }^{\mathrm{v}}$ is localization quotient of the $\mathrm{i}$-th branch (turnover), $\mathrm{v}_{\mathrm{i}}$ is the value of output (turnover) of the $i$-th branch in a region, $v$ is the value of output in the region, $V_{i}$ is the value of output (turnover) of the i-th branch in the country, $\mathrm{V}$ is the value of output in the country.

The disadvantage of this method is the simplicity and the non-systematism of the conception. Only a very simple ratio is the determinant for deciding about cluster potential. The result can be influenced by the selected factor (employment, turnover, etc.) which may not be correct.

The input-output analysis, represented by localization quotients, can also show those industrial branches where many employees are needed. However, there is no relation between employment number and the participation of a firm in cluster.

Based on the presented reasons we suggest a statistical method based on Porter diamond and localization quotients $\mathrm{LQ}_{\mathrm{i}}^{\mathrm{v}}$ of the $\mathrm{i}$-th branch (turnover, employees) for the identification of industrial clusters. The essence of the proposed method lies in the analysis of empirical data using multivariate statistical methods (hierarchical principal component analysis). The data are represented by different business climate factors (acc. Porter 1998). The method remains general enough to be interpreted for different industrial branches. 
When large multivariate datasets are analyzed, it is often desirable to reduce their dimensionality. Principal component analysis (PCA) is one of the techniques in accomplishing this. For the same purpose, independent component analysis, neural networks, and other methods are also at disposal (see e.g. Hyvärinen et al. 2001). Principal component analysis replaces the $m$ original variables by a smaller number $f$ of derived variables, the principal components, which are linear combinations of the original variables. However, this can be impossible in some cases. Since PCA has been described by other authors so far, only a brief notion of PCA is given here.

Let $\mathbf{X}$ represent a data matrix $n * m$, where $n$ is the number of observations, and $m$ is the number of variables. Principal component analysis represents an optimal factorization of $\mathrm{X}$ into two matrices, $\mathbf{T}$ (scores matrix, $\mathrm{n} * \mathrm{f}, \mathrm{f}$ is the number of factors, $\mathrm{f}<\mathrm{m}$ ) and $\mathbf{P}$ (loadings matrix, $\left.\mathrm{m}^{*} \mathrm{f}\right)$, plus a matrix of residuals $\mathbf{E}\left(\mathrm{n}^{*} \mathrm{~m}\right)$. The PCA model can be defined as follows:

$$
\mathbf{X}=\mathbf{T} \times \mathbf{P}^{\mathrm{T}}+\mathbf{E} .
$$

The principle of this method lies in the fact that a variable with a higher variation explains a higher proportion of the variation in the dependent variable compared to a variable with a lesser variation. So, the original set of variables $\mathrm{x}_{1}, \mathrm{x}_{2}, \ldots, \mathrm{x}_{\mathrm{m}}$ is transformed into the set of factors $\mathrm{C}_{1}, \mathrm{C}_{2}, \ldots, \mathrm{C}_{\mathrm{f}}$. The factors $\mathrm{C}_{1}, \mathrm{C}_{2}, \ldots, \mathrm{C}_{\mathrm{f}}$ are uncorrelated and represent most of the original variation. The condition for optimal solution is that the Euclidean norm of residual matrix $\|\mathbf{E}\|$ must be minimized for the given number $f$ of factors $\mathrm{C}_{1}, \mathrm{C}_{2}, \ldots, \mathrm{C}_{\mathrm{f}}$. In order to reach the optimal solution, the columns of matrix $\mathbf{P}$ are the eigenvectors corresponding to the $\mathrm{f}$ largest eigenvalues of the covariance matrix $\mathbf{X}$.

In order to get more detailed results, we decided to apply the hierarchical multi-block PCA method (Janné 2001). The hierarchical multi-block PCA may be used by calculating PCAs from each of a number of blocks constructed from the data matrix X. These variables are then used for the subsequent PCA calculations. This technique reduces the systematic but unwanted error in the data while still conserving all essential information in the data. The biggest advantage of this technique is that it gives an easier interpretation of the correlation between scores and loadings, as the loading plot will contain fewer variables than the original data set. It might also be possible to choose "blocks" of the data corresponding to different methods of industrial clusters identification and thereby their results can be compared together with the correlations between the methods.

The model suggestion for competitive advantage analysis of industrial clusters by hierarchical multi-block PCA is presented in Figure 2.

The values of variables $\mathrm{x}_{1}, \mathrm{x}_{2}, \ldots, \mathrm{x}_{11}$ represent the inputs of the hierarchical multi-block PCA model. The data should be pre-processed e.g. by means of standardization (Jolliffe 1986), as the dependency on units is removed. The variables are divided into specific blocks according to the competitiveness determinants of industrial clusters (inputs, firms strategy, demand, related industries, localization quotient). Their outputs $\left(\mathrm{y}_{1}, \mathrm{y}_{2}, \ldots, \mathrm{y}_{5}\right)$ are used as the inputs of the final block. Based on the analysis of the final block outputs we are able to find new variables $\mathrm{C}_{1}, \mathrm{C}_{2}, \ldots, \mathrm{C}_{\mathrm{f}}$ explaining the 
Fig. 2. The hierarchical multi-block PCA model for competitive advantage analysis of industrial clusters Legend: $x_{1}-$ human resources availability, $x_{2}-$ capital resources availability, $x_{3}$ - infrastructure availability, $\mathrm{x}_{4}-$ natural resources availability, $\mathrm{x}_{5}-$ aggressive and innovative strategy (rivalry), $x_{6}-$ investment in innovation, $x_{7}-$ demanding customers and world leaders, $x_{8}-$ local subcontractor systems, flexibility of local firms, $x_{9}$ - relations among the firms in the region are cooperative or multilateral, $\mathrm{x}_{10}$ - growth of employment, $\mathrm{x}_{11}$ - growth of turnover, $\mathrm{y}_{1}$ - inputs, $\mathrm{y}_{2}$ - firms strategy, $\mathrm{y}_{3}-$ demand, $\mathrm{y}_{4}-$ related industries, $\mathrm{y}_{5}-$ localization quotient, $\mathrm{C}_{1}, \mathrm{C}_{2}, \ldots, \mathrm{C}_{\mathrm{f}}-$ principal components

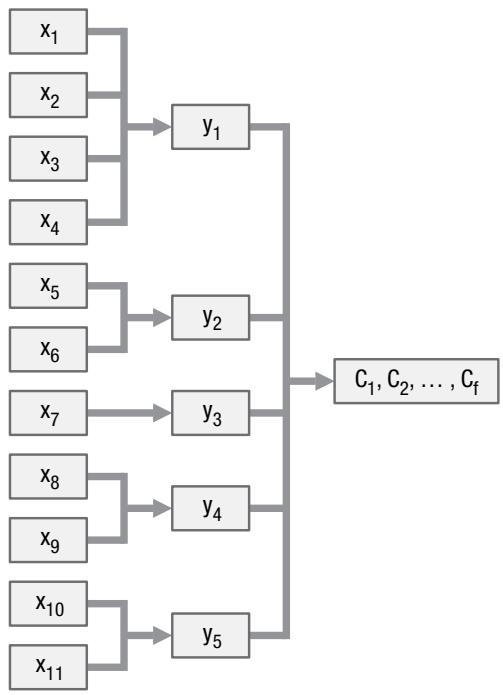

original variables $\mathrm{x}_{1}, \mathrm{x}_{2}, \ldots, \mathrm{x}_{11}$. Through this process, the final results can be easily interpreted based on competitiveness determinants of industrial clusters $\mathrm{y}_{1}, \mathrm{y}_{2}, \ldots, \mathrm{y}_{5}$. However, the results should be verified by expert examination because they are fully dependent on the panel data.

\section{Experimental results for the selected region}

The proposed hierarchical multi-block PCA model for competitive advantage analysis of industrial clusters will be verified on panel data from the Czech Republic. The assignment of a cluster potential to a sample of 142 medium and large enterprises in the Pardubice region, Czech Republic (NUTS3), represents the goal of the modelling. The representativeness of the data is guaranteed as the 142 enterprises employ $78 \%$ of all employees in the region. The enterprises are divided into industrial branches (see Table 2).

Table 2. The industrial branches of the monitored enterprises

\begin{tabular}{cc}
\hline FoI - Food industry & MaI - Machinery industry \\
\hline ChI - Chemical industry & FuI - Furniture industry \\
\hline $\mathrm{TI}-$ Textile industry & EI - Electrical industry \\
\hline MeI - Metalworking industry & BI - Building industry \\
\hline
\end{tabular}

The input data was acquired by a field research. The enterprises of Pardubice region answered questions concerning the determinants of competitive advantages (see Table $A$ and Table B in Appendix). Thereby, the values of variables $x_{1}, x_{2}, \ldots, x_{9}$ were found for each of the industry branches. After obtaining this information we can construct the Porter diamond model for major industrial branches as presented in Figure 3. In addition we used data from the Czech Statistical Office in order to calculate the localization quotients $\mathrm{x}_{10}$ and $\mathrm{x}_{11}$ (Fig. 4). 


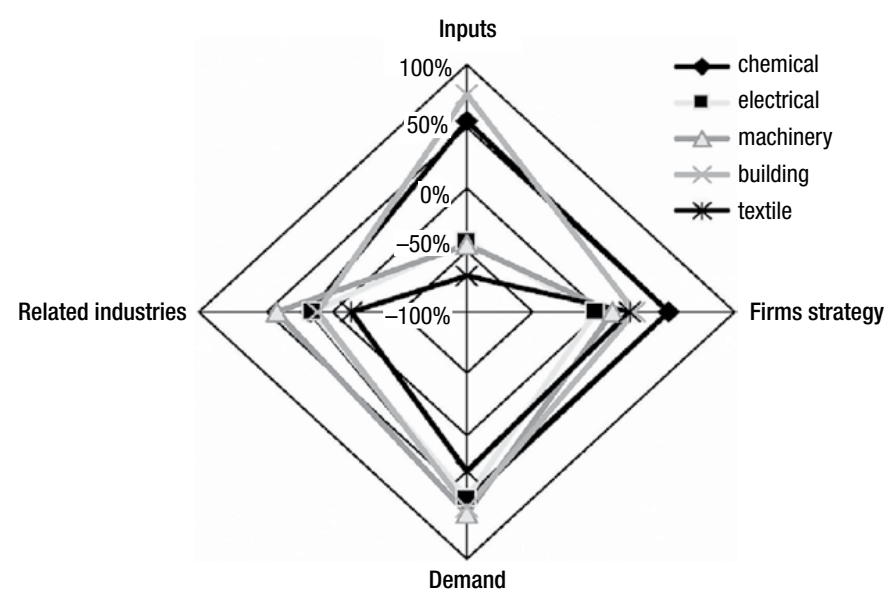

Fig. 3. The values of the determinants of competitive advantage for major industrial branches

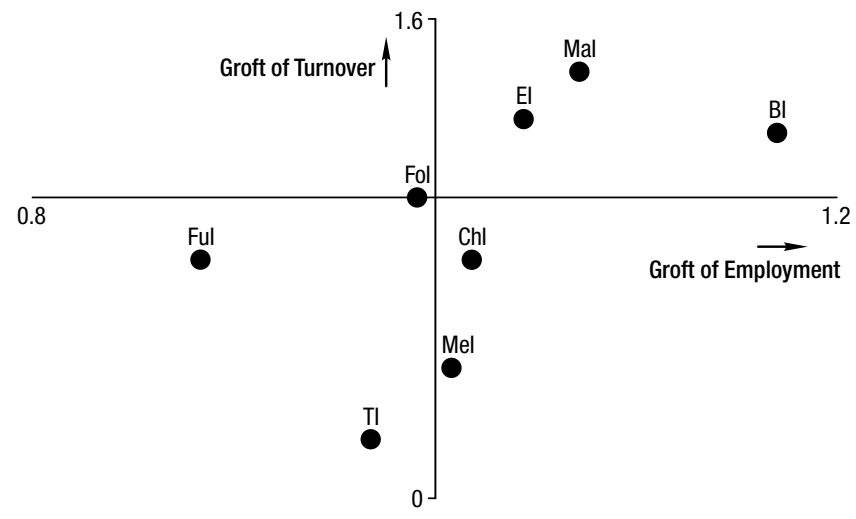

Fig. 4. Industrial clusters potential measured by localization quotients

The building and chemical industries are highly competitive according to the Porter diamond, while building, machinery and electrical industries are detected as the most potential industrial branches based on the localization quotients. The results of the localization quotients confirm the results obtained by the competitive advantage analysis. However, they show the deficiency of the localization quotients as they do not show the reasons behind, e.g. low cluster potential. The combination of these two approaches makes it possible to detect the possibilities toward higher cluster potential. For example, the electric industry (EI) needs more (or better quality) inputs available to develop its cluster potential.

First, the relations among variables will be analyzed by means of factor analysis with the intention to confirm the dependencies of the variables for the competitive advantage analysis and the localization quotients. The factor analysis is realized in order to find relationships between input variables. Thus, the first insight in the data is realized. As presented in Figure 5, two factors F1 and F2 have been found and the rotation procedure 


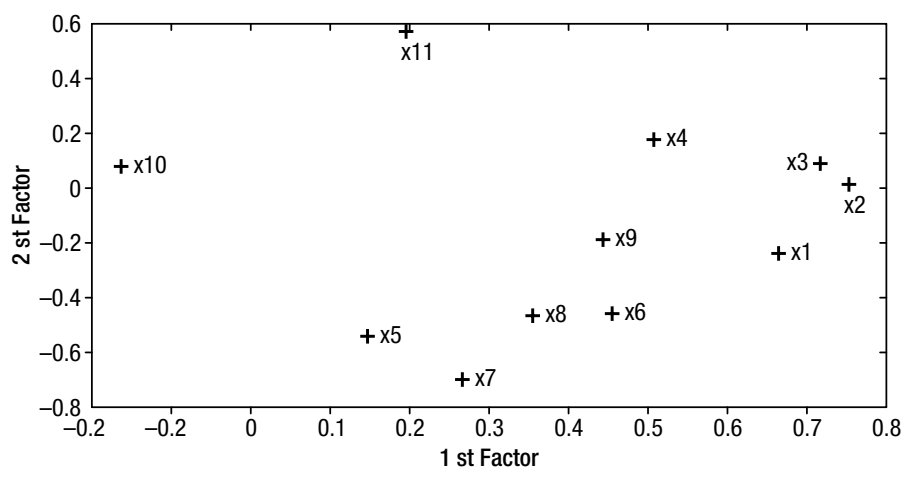

Fig. 5. Factor loadings obtained after normalized quatrimax rotational strategy

(normalized quatrimax) has been applied to obtain clear results. Based on the results, four groups of variables can be extracted, i.e. resources availability $\left(\mathrm{x}_{1}, \mathrm{x}_{2}, \mathrm{x}_{3}\right.$ and $\left.\mathrm{x}_{4}\right)$, other parts of the Porter diamond (firms strategy, demand and related industries, i.e. $\mathrm{x}_{5}, \mathrm{x}_{6}, \ldots, \mathrm{x}_{9}$ ) and the two localization quotients $\mathrm{x}_{10}$ and $\mathrm{x}_{11}$.

After the first insight, it is clear that there are two main factors representing the original data, the first factor representing resources availability $\left(\mathrm{x}_{1}, \mathrm{x}_{2}, \mathrm{x}_{3}\right.$ and $\left.\mathrm{x}_{4}\right)$, and the second factor representing demand and growth of turnover on one side and related industries and firms strategy on the other side.

The relations among the variables confirmed the fact that it is suitable to investigate the blocks of variables individually because the variables are linked strongly within each block. Further, we can examine the influence of these blocks of variables on a total cluster potential. Therefore, the modelling is realized by the hierarchical multi-block PCA. The results of the model are presented in Table 3.

The goal of the PCA modelling is the reduction of 5 input variables $\mathrm{y}_{1}, \mathrm{y}_{2}, \ldots, \mathrm{y}_{5}$ to a less number $f$ of variables $C_{1}, C_{2}, \ldots, C_{f}$ which represent most of the variation. The results of the experiments show that it is suitable to create only one component $\mathrm{C}_{1}$.

Table 3. Average component scores for individual branches

\begin{tabular}{ccccccc}
\hline Branch & $\mathrm{y}_{1}$ & $\mathrm{y}_{2}$ & $\mathrm{y}_{3}$ & $\mathrm{y}_{4}$ & $\mathrm{y}_{5}$ & $\mathrm{C}_{1}$ \\
\hline FoI & 0.45 & -0.18 & -1.74 & -0.74 & 0.15 & -0.55 \\
\hline ChI & 0.49 & 0.66 & 0.89 & -0.08 & 0.10 & 0.51 \\
\hline TI & -0.53 & -0.02 & -0.39 & -0.76 & -0.42 & -0.39 \\
\hline MeI & -0.40 & -0.06 & -0.31 & 0.67 & -0.25 & -0.06 \\
\hline MaI & -0.43 & -0.03 & 1.04 & 0.51 & 0.45 & 0.29 \\
\hline FuI & -0.14 & -0.52 & -1.18 & -0.14 & -0.35 & -0.53 \\
\hline EI & -0.50 & -0.24 & 1.01 & 0.07 & 0.54 & 0.12 \\
\hline BI & 0.49 & 0.10 & 0.69 & 0.00 & 0.29 & 0.33 \\
\hline
\end{tabular}


The first component $\mathrm{C}_{1}$ represents $39.21 \%$ of the input data variation. Further, its eigenvalue is higher than the given threshold value 1 .

According to the results presented in Table 3, the strengths and weaknesses of the selected industrial branches can be identified (positive values show the above-average potential for clustering; while negative values show the below-average potential for clustering). The results support the outcomes from previous analysis; the chemical, machinery, and building industry have the highest cluster potential in the analyzed region. Moreover, several important and helpful information was obtained from the analysis. The electrical industry has some problems concerning a lack of sources (in quality, range of inputs, etc.). They suffer from unsuitable strategies created by firms within their branch (this criterion can reduce the cluster potential, in EI branch, less than the lack of inputs). The branch with the smallest cluster potential is the food industry in spite of the localization quotients showing that there is an ability of clustering in this branch.

The unambiguous results from the methods and models lead us to the result that the component score $\mathrm{C}_{1}$ can be recommended for industrial clusters identification in two cases. First, it is suitable to use it if there is a possibility of cluster birth in the branch. Second, it can be used for the identification of industrial branches where only the cooperation or business chains and networks are developed. The lowest values can show insufficient conditions for a potential significant cooperation that can represent a competitive advantage for interested firms.

The loadings (weights) of input variables $\mathrm{y}_{1}, \mathrm{y}_{2}, \ldots, \mathrm{y}_{5}$ in the first component $\mathrm{C}_{1}$ are presented in Table 4. According to this, the first component $\mathrm{C}_{1}$ can be represented mainly by the variables $\mathrm{y}_{1}, \mathrm{y}_{2}, \mathrm{y}_{3}$ and $\mathrm{y}_{4}$, while the localization quotients play an unimportant role. Localization quotients are important for the second component $\mathrm{C}_{2}$ which is, however, statistically insignificant, explaining only a low percentage of the input data variation.

Table 4. Factor loadings of input factors $\mathrm{y}_{1}, \mathrm{y}_{2}, \ldots, \mathrm{y}_{5}$

\begin{tabular}{ccc}
\hline & $\mathrm{C}_{1}$ & $\mathrm{C}_{2}$ \\
\hline $\mathrm{y}_{1}$ & 0.22 & 0.05 \\
\hline $\mathrm{y}_{2}$ & 0.28 & 0.00 \\
\hline $\mathrm{y}_{3}$ & 0.26 & 0.01 \\
\hline $\mathrm{y}_{4}$ & 0.20 & 0.07 \\
\hline $\mathrm{y}_{5}$ & 0.04 & 0.87 \\
\hline
\end{tabular}

According to these results, the most significant factors of competitive advantage analysis are firms strategy and demand, followed by resources availability and related industries. Localization quotient has only a low impact on the resulting score $\mathrm{C}_{1}$. Based on these loadings, the values of the first component $\mathrm{C}_{1}$ (cluster potential $\mathrm{CP}$ ) for the individual industry branches can be calculated in the following way:

$$
\mathrm{CP}=0.22 \times \mathrm{y}_{1}+0.28 \times \mathrm{y}_{2}+0.26 \times \mathrm{y}_{3}+0.20 \times \mathrm{y}_{4}+0.04 \times \mathrm{y}_{5} .
$$


In determining industrial cluster potential, and also for industrial branches in other regions, the following steps have to be realized:

An evaluation of the determinants of competitive advantage (resources availability, firms' strategy, demand, and related industries). This evaluation can be based either on panel data or on an expert's opinion. In the case of an expert's opinion, the expert should be at least able to determine whether the determinants are at an average $(0)$, above-average $(+)$, or below-average $(-)$ level. In a similar manner, the values of the localization quotients should be transformed so that the value LQ $=1$ represents an average value (0), while $\mathrm{LQ}<1$ is below-average $(-)$ and $L Q>1$ is above-average $(+)$. When the evaluation of inputs is completed, the industrial cluster potential CP can be determined according to equation 6. Again, the results can be interpreted in a similar way. Positive values mean an above-average industrial cluster potential, while negative values shows a below-average industrial cluster potential.

\section{Conclusion}

Conducted research has proved the evidence that the clusters and entrepreneur chains and business networks have a positive influence on regional development. They belong to the important tools of regional development in many developed countries all over the world. But in all economies public finances must be spent efficiently, that is the reason for development of new tools that can help measure industrial cluster potential. Information regarding potential is needed by industrial clusters, cooperation chains, and business networks in various industrial branches.

Many methods for the measurement of spatial concentration, industrial specialization, or agglomeration advantages are commonly used at a regional or local level. High quality data and information are necessary for the rigorous methods used in practice. "Hard" data can be obtained from statistical reviews or agencies. But the reality is not that ideal, statistical data are not divided into desired groups and levels of the industries in the economy. Many sorts of data are not available at all, they are either useless or they are of poor quality. There are many imperfections in the group of quantitative methods, especially:

- high dependence on the quality of input data,

- less factors on which the result depends (mostly one-factor models),

- complexity of the computations,

- un-definiteness of the result (Only one number is often the result. This result must be interpreted by the researcher or specialist in regional science. The interpretations are not objective, but they are depended by their opinions and experiences).

If the quantitative methods are not feasible, qualitative methods can be used. These methods have also some limitations. The results are fully depended on the specialist (expert) and his opinion. Coming from the practical application we can certify that these methods provide results of higher quality.

The described imperfections can cause the methods to not to be applicable. A new method was proposed in this paper. This method can eliminate some of the described 
limitations, and, moreover, it can use most of the advantages from both groups of methods (for example: more factors can be analyzed; results are based on panel data; unambiguous results; easily interpretable and applicable). The method for competitive advantage analysis of the industrial cluster uses the knowledge of the micro-economic environment via the top managers of the firms (the respondents), uses the capability of the Porter's diamond model thesis and its four forces of competitive advantage for the industrial cluster birth and existence. Since many responses are obtained for each industrial branch, multivariate statistical methods which help process the data matrix are suitable to use. They can help with data understanding, especially in the search for the dependences among the input variables. An easy interpretation of the results is available when using hierarchical multi-block PCA.

The ability to show the strengths and weaknesses of the industrial branches in the analyzed region is the next advantage of the proposed model. Every force can be analyzed separately and more detailed information can be obtained for each of them (for example, insufficient factors which can be improved by a better cooperation and support from regional authorities, or more effective regional networks among regional players). None of the prior methods can provide all of these possibilities.

The proposed method was also verified in this paper. The results were exact, which was verified by an independent expert examination (qualitative method). Next, the hypothesis regarding other factors (except for the four forces) that influence the cluster potential was analyzed and computed. The hypothesis was not verified. In Table 4, one can find the results which can help identify the weights and importance of the analyzed factors in selected industrial branches in the analyzed region.

According to the component $\mathrm{C}_{1}$ (cluster potential) we are able to make the following recommendations whether an industrial cluster can be established, or if only cooperation within the entrepreneur networks or chains should be established. A low score value shows an insufficient precondition for any sort of important cooperation which would represent a competitive advantage in the region and bring benefits for the interested firms.

We must mention that methods providing normative rather than positive results are preferred in practice.

The described method depends on the quantity and quality of empirical data. If the researchers have all required data at the level of NUTS2 regions, they can analyze them and, thus, obtain an overview of the potential for Porterian industrial clusters. Contemporary clusters have not to be localized in one region only. The explanatory power can be huge problem during the analysis in region NUTS2. Especially in the case of large regions, there may be additional factors and higher variability of industries which could influence the results of the analysis. Therefore, for larger regions, the list of the factors of industrial clusters' birth should be extended. 


\section{References}

Anderson, G. 1994. Industry clustering for economic development, Economic Development Review 12(2): 26-37.

Andersson, T.; Serger, S. S.; Sorwig, J.; Hansson, E. W. 2004. The Cluster Policies Whitebook. Malmö: Iked.

Bachtler, J.; Yuill, D. 2001. Policies and strategies for regional development: a shift in paradigm?, Regional and Industrial Policy Research Paper No 46.

Bergmann, E. M.; Feser, E. J. 1999. Industrial and Regional Clusters: Concepts and Comparative Applications. Virginia: WVU Regional Research Institute.

Blien, U.; Maier, G. 2008. The Economics of Regional Clusters. Viena: Viena University of Economics and Business Administration.

Bojar, E. 2007. Clusters as vehicles stimulating regional and local development, in Proceedings of ERSA Congress. Paris, University of Cergy-Pontoise.

Brachert, M.; Titze, M.; Kubis, A. 2011. Identifying industrial clusters from a multidimensional perspective: methodical aspects with an application to Germany, Papers in Regional Science 90(2): 419-439. http://dx.doi.org/10.1111/j.1435-5957.2011.00356.x

Braczyk, H. J.; Cooke, P.; Heidenreich, M. 1998. Regional Innovation Systems: the Role of Governances in a Globalized World. London: Routledge.

Brenner, T. 2001. Simulating the evolution of localised industrial clusters - an identification of the basic mechanisms, Journal of Artificial Societies and Social Simulation 4(3).

Camagni, R. P. 1995. The concept of innovative milieu and its relevance for public policies in European lagging regions, Papers in Regional Science 74(4): 317-340.

Cooke, P. 2002. Knowledge Economies. London: Routledge.

Cooke, P.; Gomez Uranga, M.; Etxebarria, G. 1997. Regional innovation systems: institutional and organisational dimensions, Research Policy 26(4-5): 475-491.

http://dx.doi.org/10.1016/S0048-7333(97)00025-5

Duranton, D.; Puga, D. 2000. Diversity and specialisation in cities: why, where and when does it matter?, Urban Studies 37(3): 535-555.

Ellison, G.; Glaeser, E. 1997. Geographic concentration in U.S. manufacturing industries: a dartboard approach, Journal of Political Economy 105(5): 889-927. http://dx.doi.org/10.1086/262098 Feser, E. J.; Bergmann, E. M. 2000. National industry cluster templates: a framework for applied regional cluster analysis, Regional Studies 34(1): 1-19.

http://dx.doi.org/10.1080/00343400050005844

Fioretti, G. 2006. Agent-based models of industrial clusters and districts, in Progress in Economic Research. New York: Nova Science Publishers, 125-142.

Fritsch, M.; Mueller, P. 2004. Effects of new business formation on regional development over time, Regional Studies 38(7): 961-975. http://dx.doi.org/10.1080/0034340042000280965

Ginevicius, R. 2010. The effectiveness of cooperation of industrial enterprises, Journal of Business Economics and Management 11(2): 283-296. http://dx.doi.org/10.3846/jbem.2010.14

Goetz, S.; Deller, S.; Harris, T. 2007. Targeting Regional Economic Development: an Outline of a National Extension Educational Program. Wiskonsin, CDS annual meetings.

Hajkova, V.; Hajek, P. 2009. Learning regions identification by unsupervised methods, in 3rd Central European Conference in Regional Science. Kosice, Technical University of Kosice, 1037-1048.

Hajkova, V.; Hajek, P. 2011. Typology of regional innovation systems in Europe - a neural network approach, International Journal of Mathematical Models and Methods in Applied Sciences 3(5): $463-471$. 
Hyvärinen, A.; Karhunen, J.; Oja, E. 2001. Independent Component Analysis. New York: John Wiley and Sons.

Janné, K.; Pettersen, J.; Lindberg, N.-O.; Lundtstedt, T. 2001. Hierarchical principal component analysis (PCA) and projection to latent structure (PLS) technique on spectroscopic data as a data pretreatment for calibration, Journal of Chemometrics 15(4): 203-213.

http://dx.doi.org/10.1002/cem.677

Jolliffe, I. T. 1986. Principal Component Analysis. New York: Springer-Verlag.

Karlsson, Ch. 2008. Handbook of Research on Innovation and Clusters. Jönsköping: Jönsköping University.

Luo, S. X.; Yan, J. Z. 2009. Analysis of regional industrial clusters' competitiveness based on identification, in ECBI 2009: Int. Conf. on Electronic Commerce and Business Intelligence. Beijing, 471-474. http://dx.doi.org/10.1109/ECBI.2009.57

Maier, G. 2007. Cluster policy: a strategy for boosting competitiveness and wasting money?, in Proceedings from 2nd CERS. Kosice, Technical University in Kosice, 17-28.

Marshall, A. 1890. Principles of Economics. London: Macmillan.

Maurel, F.; Sédillot, B. 1999. A measure of the geographic concentration in french manufacturing industries, Regional Sceince and Urban Economics 29: 575-604.

http://dx.doi.org/10.1016/S0166-0462(99)00020-4

Nowicka-Skowron, M.; Pachura, P. 2010. Theory of innovation in spatial perspective, Polish Journal of Management Studies 1(1): 111-118.

OECD 2001. Innovative Clusters: Drivers of National Innovation Systems. Paris, OECD.

Pachura, P. 2010. Regional Cohesion. New York: Springer-Verlag.

http://dx.doi.org/10.1007/978-3-7908-2364-6

Pavelkova, D. 2009. Clusters and Their Impact on Firms Performance. Prague: Grada.

Porter, M. E. 1990. The Competitive Advantage of Nations. New York: The Free Press.

Porter, M. E. 1998. On Competition. Boston: Harvard Business School.

Porter, M. E. 1998b. Clusters and the new economics of competition, Harvard Business Review 76(6): 77-90.

Rehak, S.; Pastor, R. 2008. From barriers identification of knowledge economy in regions to their overcoming, in Proc. of Int. Economic Conference in Bratislava. Bratislava, Economic University of Bratislava.

Reynolds, P.; Storey, D. J.; Westhead, P. 1994. Cross-national comparison in the variation in new firm formation rares, Regional Studies 28(4): 443-456.

http://dx.doi.org/10.1080/00343409412331348386

Skokan, K. 2008. Triple helix and regional systems of innovation, in Proceedings of Int. Economic Conference in Bratislava. Bratislava, Economic University of Bratislava.

Stejskal, J. 2007. Analysis of the Cluster and Innovation Potential in Pardubice Region. Pardubice, University of Pardubice.

Stejskal, J. 2009. Competitiveness advantage analysis as one method for cluster identification in regions, in 3rd Central European Conference in Regional Science. Kosice, Technical University of Kosice, 1337-1346.

Stejskal, J. 2011. Analysis of the applicability of selected methods for industrial clusters identifying, International Journal of Systems Applications, Engineering and Development 3(5): 255-262.

Stejskal, J.; Hajek, P. 2008. The influence of business climate on industrial clusters, South Asian Journal of Socio-Political Studies 9(1): 44-47. 
Sternberg, R. 2007. Innovative new firms, embeddedness and regional development, International Journal of Entrepreneurship and Innovation Management 7(2-5): 445-461.

http://dx.doi.org/10.1504/IJEIM.2007.012893

Sternberg, R.; Litzenberger, T. 2004. Regional clusters in Germany: their geography and their relevance for entrepreneurial activities, European Planning Studies 12(6): 767-791.

http://dx.doi.org/10.1080/0965431042000251855

Storper, M. 1995. The resurgence of regional economics, ten years later: the region as a nexus of untraded interdependencies, European Urban and Regional Studies 2(3): 191-221. http://dx.doi.org/10.1177/096977649500200301

Titze, M.; Mrachert, M.; Kubis, A. 2011. The identification of regional industrial clusters using qualitative input-output analysis (QIOA), Regional Studies 45(1): 89-102.

http://dx.doi.org/10.1080/00343400903234688

Tödtling, F.; Lengauer, L.; Trippl, M. 2007. Start-ups and Innovation in the Viena ICT sector: how important is the local cluster?, in Proceedings of European Regional Science Association Congress. Paris, University of Cergy-Pontoise.

Zizka, M. 2004. Methods of industrial clusters identification, Economics and Management 7(4): $32-46$. 


\section{APPENDIXES}

Table A. Absolute frequencies of answers' evaluation

\begin{tabular}{|c|c|c|c|c|c|c|c|c|c|c|}
\hline & FoI & ChI & TI & MeI & MaI & FuI & EI & $\mathrm{BI}$ & others* & total \\
\hline $\mathrm{x}_{1}$ & \multicolumn{10}{|c|}{ human resources availability } \\
\hline positive & 2 & 1 & 1 & 1 & 2 & 0 & 1 & 2 & 3 & 13 \\
\hline rather positive & 2 & 8 & 4 & 2 & 9 & 3 & 5 & 10 & 1 & 44 \\
\hline rather negative & 2 & 6 & 5 & 10 & 6 & 5 & 6 & 7 & 2 & 49 \\
\hline negative & 1 & 0 & 2 & 2 & 2 & 1 & 2 & 2 & 1 & 13 \\
\hline $\mathrm{x}_{2}$ & \multicolumn{10}{|c|}{ capital resources availability } \\
\hline positive & 1 & 2 & 0 & 1 & 2 & 2 & 0 & 1 & 1 & 10 \\
\hline rather positive & 5 & 6 & 3 & 5 & 4 & 1 & 4 & 10 & 3 & 41 \\
\hline rather negative & 0 & 3 & 6 & 6 & 11 & 5 & 6 & 6 & 1 & 44 \\
\hline negative & 1 & 2 & 2 & 2 & 1 & 1 & 2 & 2 & 1 & 14 \\
\hline $\mathrm{x}_{3}$ & \multicolumn{10}{|c|}{ infrastructure availability } \\
\hline positive & 1 & 4 & 1 & 0 & 1 & 1 & 0 & 4 & 2 & 14 \\
\hline rather positive & 2 & 4 & 4 & 6 & 8 & 4 & 9 & 11 & 3 & 51 \\
\hline rather negative & 2 & 3 & 5 & 8 & 6 & 2 & 1 & 3 & 1 & 31 \\
\hline negative & 1 & 2 & 2 & 0 & 2 & 1 & 4 & 2 & 0 & 14 \\
\hline $\mathrm{x}_{4}$ & \multicolumn{10}{|c|}{ natural resources availability } \\
\hline positive & 0 & 1 & 1 & 0 & 1 & 0 & 0 & 1 & 0 & 4 \\
\hline rather positive & 1 & 5 & 2 & 3 & 2 & 2 & 2 & 8 & 2 & 27 \\
\hline rather negative & 3 & 1 & 0 & 5 & 8 & 3 & 3 & 2 & 1 & 26 \\
\hline negative & 1 & 5 & 4 & 3 & 4 & 2 & 3 & 5 & 1 & 28 \\
\hline $\mathrm{x}_{5}$ & \multicolumn{10}{|c|}{ aggressive and innovative strategy (rivalry) } \\
\hline positive & 1 & 0 & 2 & 2 & 2 & 0 & 1 & 2 & 4 & 14 \\
\hline rather positive & 1 & 11 & 5 & 5 & 8 & 3 & 3 & 9 & 1 & 46 \\
\hline rather negative & 4 & 2 & 3 & 7 & 9 & 3 & 4 & 5 & 0 & 37 \\
\hline negative & 2 & 1 & 2 & 2 & 0 & 3 & 4 & 5 & 1 & 20 \\
\hline $\mathrm{x}_{6}$ & \multicolumn{10}{|c|}{ investment in innovation } \\
\hline positive & 3 & 7 & 2 & 4 & 0 & 2 & 5 & 4 & 1 & 28 \\
\hline rather positive & 2 & 5 & 6 & 4 & 11 & 4 & 3 & 11 & 5 & 51 \\
\hline rather negative & 2 & 3 & 1 & 7 & 7 & 2 & 3 & 3 & 1 & 29 \\
\hline negative & 1 & 0 & 3 & 1 & 1 & 2 & 2 & 1 & 0 & 11 \\
\hline $\mathrm{x}_{7}$ & \multicolumn{10}{|c|}{ demanding customers and world leaders } \\
\hline positive & 1 & 8 & 4 & 3 & 8 & 2 & 7 & 9 & 4 & 46 \\
\hline rather positive & 2 & 4 & 4 & 8 & 9 & 3 & 3 & 8 & 3 & 44 \\
\hline
\end{tabular}


End of Table $A$

\begin{tabular}{lcccccccccc}
\hline & FoI & ChI & TI & MeI & MaI & FuI & EI & BI & others* & total \\
\hline rather negative & 4 & 2 & 2 & 1 & 2 & 2 & 3 & 1 & 1 & 18 \\
\hline negative & 1 & 1 & 2 & 2 & 0 & 2 & 0 & 2 & 0 & 10 \\
\hline $\mathrm{x}_{8}$ & \multicolumn{7}{c}{ local subcontractor systems, flexibility of local firms } \\
\hline positive & 0 & 2 & 0 & 3 & 4 & 1 & 1 & 3 & 2 & 16 \\
\hline rather positive & 4 & 8 & 4 & 8 & 12 & 5 & 8 & 9 & 3 & 61 \\
\hline rather negative & 3 & 4 & 4 & 4 & 3 & 1 & 3 & 4 & 2 & 28 \\
\hline negative & 1 & 1 & 3 & 1 & 0 & 2 & 1 & 6 & 0 & 15 \\
\hline \multicolumn{1}{c}{$\mathrm{x}_{9}$} & relations among the firms in the region are cooperative or multilateral \\
\hline positive & 0 & 0 & 0 & 3 & 0 & 0 & 1 & 3 & 1 & 8 \\
\hline rather positive & 1 & 5 & 4 & 9 & 13 & 4 & 3 & 7 & 2 & 48 \\
\hline rather negative & 4 & 6 & 3 & 3 & 5 & 2 & 4 & 4 & 1 & 32 \\
\hline negative & 1 & 1 & 2 & 0 & 1 & 1 & 3 & 2 & 0 & 11 \\
\hline
\end{tabular}

Note: *the other firms are not included in further calculation

Table B. Relative evaluations for industrial branches [\%]

\begin{tabular}{ccccccccc}
\hline & FoI & ChI & TI & MeI & MaI & FuI & EI & BI \\
\hline $\mathrm{x}_{1}$ & 10 & 18 & -14 & -47 & 13 & -25 & -14 & 13 \\
\hline $\mathrm{x}_{2}$ & 50 & 18 & -36 & -11 & -25 & -25 & -29 & 13 \\
\hline $\mathrm{x}_{3}$ & 0 & 18 & -14 & -11 & 4 & 17 & 29 & 42 \\
\hline $\mathrm{x}_{4}$ & -30 & 0 & -7 & -26 & -38 & -25 & -29 & 8 \\
\hline $\mathrm{x}_{5}$ & -40 & 47 & 14 & -11 & 4 & -25 & -29 & 4 \\
\hline $\mathrm{x}_{6}$ & 20 & 53 & 29 & 0 & 13 & 17 & 21 & 46 \\
\hline $\mathrm{x}_{7}$ & -20 & 53 & 29 & 42 & 63 & 8 & 50 & 58 \\
\hline $\mathrm{x}_{8}$ & 0 & 29 & -21 & 32 & 54 & 25 & 36 & 8 \\
\hline $\mathrm{x}_{9}$ & -40 & -12 & -7 & 47 & 29 & 8 & -21 & 17 \\
\hline
\end{tabular}

Jan STEJSKAL is a senior lecturer with the Institute of Economics, Faculty of Economics and Administration, University of Pardubice, Czech Republic. His domain is connection of the public economy in the regional scope and view. Especially, he analyzes regional policy, tools of the local and regional economical development, after care strategies for investors, and systems of support in EU countries.

Petr HAJEK is a senior lecturer with the Institute of System Engineering and Informatics, Faculty of Economics and Administration, University of Pardubice, Czech Republic. He deals with the modelling (prediction, classification, and optimization) of economic processes (especially in the field of public economics and public finance), advanced statistical methods, and methods of computational intelligence (soft-computing). 